\title{
Siderite nucleation pathways as a function of aqueous solution saturation state at $25^{\circ} \mathrm{C}$
}

\author{
Josephina J.P.A. Mulders ${ }^{a}$, Dominique J. Tobler ${ }^{b} \&$ Eric H. Oelkers $^{a, c^{*}}$
}

${ }^{a}$ Earth Sciences, University College London, Gower Street, WC1E 6BT London, United Kingdom

${ }^{b}$ Nano-Science Center, Department of Chemistry, University of Copenhagen, Copenhagen, 2100 Denmark

${ }^{\mathrm{c}}$ GET-Université de Toulouse-CNRS-IRD-OMP, 14 Avenue Edouard Belin, 31400 Toulouse, France

"Corresponding author: e.oelkers@ucl.ac.uk

KEYWORDS siderite, nucleation mechanisms, saturation state, amorphous ferrous carbonate

\begin{abstract}
The mechanisms of siderite $\left(\mathrm{FeCO}_{3}\right)$ nucleation from aqueous solution depend on the fluid saturation state. In this study we investigate the effect of aqueous fluid saturation on the nucleation pathway of siderite. Thereof, we performed a series of turbidity and batch experiments. Turbidity measurements indicate that at low saturation indices $(\mathrm{SI}<3.69)$, siderite nucleation proceeds via the direct nucleation of crystalline siderite from the aqueous fluid. The direct precipitation of crystalline siderite is confirmed by X-Ray diffraction (XRD) analysis. This is the first study to report the direct nucleation of siderite at near-equilibrium conditions. At higher saturation indices $(\mathrm{SI} \geq 3.69)$, nucleation proceeds via the initial precipitation of amorphous ferrous carbonate (AFC) followed by the nucleation and growth of crystalline
\end{abstract}


siderite. XRD spectra confirm the initial precipitation of AFC and its transformation to crystalline siderite. Such differences in the nucleation mechanism likely affect both the reactivity of the resulting siderite and its isotopic composition. Insight into the aqueous fluid saturation state during siderite nucleation could thus be crucial for the accurate interpretation of the isotopic signature in natural systems.

\section{HIGHLIGHTS}

- Siderite nucleation at conditions close to equilibrium follows a classical nucleation pathway, with crystalline siderite nucleating directly from the aqueous solution.

- At high initial solution fluid saturation states, siderite precipitation proceeds via the initial nucleation of amorphous ferrous carbonate phases followed by dehydration and crystallization to siderite.

- Differences in siderite nucleation mechanisms can affect both the reactivity and the isotopic signature of the synthesized material.

\section{INTRODUCTION}

Siderite $\left(\mathrm{FeCO}_{3}\right)$ is the most common carbonate precipitate in iron bearing reduced environments on the Earth's surface and shallow subsurface (Fisher et al., 1998; Hangari et al., 1980). Prior to the great oxygenation event, the abiotic nucleation and precipitation of siderite was ubiquitous in oceans, as evidenced by the widespread occurrence of this mineral in the geological record (Holland, 1972, 1984). Under the present oxygen rich atmosphere, the abiotic precipitation of siderite is observed in a wide variety of naturally reduced, iron rich environments, including lake sediments, peaty soils, swamps (McMillan and Schwertmann, 1998; Postma, 1983, 1982) and hydrothermal systems (Bouzenoune and Lécolle, 1997; Chovan 
and Ozdin, 2003; Shikazono, 1977). Siderite has also been used to remediate acid mine waste waters, as siderite dissolution facilitates the increase of $\mathrm{pH}$ of the waters, while simultaneously scavenging mobile metals via the secondary precipitation of iron-oxy-hydroxides (Erdem et al., 2004; Erdem and Özverdi, 2005). Siderite can also form as a result of $\mathrm{CO}_{2}$ interaction with basaltic rock during carbon capture and storage efforts at reduced conditions, thereby facilitating $\mathrm{CO}_{2}$ mineral storage (Matter et al., 2009; Snæbjörnsdóttir et al., 2017). The widespread occurrence of siderite in natural environments and the potential importance of siderite in industrial processes have led to a growing number of studies investigating siderite nucleation and growth mechanisms (Jiang and Tosca, 2019, 2020; Jimenez-Lopez and Romanek, 2004; MontesHernandez and Renard, 2016).

Several studies describe the nucleation pathway of siderite in aqueous solutions containing high $\mathrm{Fe}^{2+}$ and bicarbonate concentrations $\left(\mathrm{Fe}^{2+}\right.$ and $\mathrm{HCO}_{3}{ }^{-}$concentration that exceed $\left.100 \mathrm{mM}\right)$ (Dideriksen et al., 2015; Jiang and Tosca, 2019, 2020; Jimenez-Lopez and Romanek, 2004), but to date there are no studies investigating the nucleation pathway of siderite at close to equilibrium conditions. At near-equilibrium conditions siderite can be supersaturated while the nucleation of amorphous ferrous carbonates (AFC) is thermodynamically unfavorable. Far from equilibrium, siderite nucleation proceeds via the initial nucleation of $\mathrm{AFC}$, followed by its dehydration and crystallization to form siderite (Dideriksen et al., 2015; Jiang and Tosca, 2019, 2020). For example, Dideriksen et al. (2015) investigated the precipitation of siderite at $\mathrm{pH} 6.6$, in aqueous solutions initially containing either $0.1 \mathrm{M} \mathrm{HCO}_{3}{ }^{-}$and $0.1 \mathrm{M} \mathrm{Fe}^{2+}$, or $0.1 \mathrm{M} \mathrm{CO}_{3}{ }^{2-}$ and $0.1 \mathrm{M} \mathrm{Fe}^{2+}$. They found that AFC nucleated in all their experiments, followed by siderite precipitation. Montes-Hernandez and Renard (2016) traced the transformation of AFC to siderite over time in a concentrated aqueous $\mathrm{Fe}^{2+}$ slurry exposed to 50 bar $\mathrm{CO}_{2}(\mathrm{~g})$ pressure. In these 
experiments AFC crystallized to siderite, forming porous spherical crystals. Jiang and Tosca (2019, 2020) and Jimenez-Lopez and Romanek (2004) constrained siderite growth kinetics on synthesized siderite seed material. These growth experiments were performed at close to equilibrium conditions, but the nucleation of their seed material was performed a far from equilibrium conditions where the initial precipitation of AFC phases was favorable. To synthesize their seed material, Jimenez-Lopez and Romanek (2004) mixed aqueous solutions containing $150 \mathrm{mM} \mathrm{HCO}_{3}^{-}$and $150 \mathrm{mM} \mathrm{Fe}^{2+}$ in batches, while Jiang and Tosca $(2019,2020)$ synthesized siderite by titrating an aqueous $1 \mathrm{M} \mathrm{HCO}_{3}^{-}$solution into an aqueous $100 \mathrm{mM} \mathrm{Fe}^{2+}$ solution. Both studies observed the initial precipitation of an amorphous phase and JimenezLopez and Romanek (2004) noted that the morphology of their precipitated material continuously changed over a year-long period, with the precipitates becoming increasingly more crystalline and rhombohedral over time.

Although siderite synthesis at far from equilibrium conditions appropriately describes the siderite nucleation mechanisms relevant to industrial applications, it likely does not provide a model for siderite nucleation in natural environments, where aqueous fluids tend to be at close to equilibrium conditions. Some insight into the nucleation and growth mechanisms of siderite can be gained from past studies on calcite (Duckworth and Martin, 2004; Golubev et al., 2009; Montes-Hernandez and Renard, 2016). Studies of calcite nucleation in the presence of citrate reveal a multi-step nucleation mechanism that depends on the saturation state of the aqueous solution (Montanari et al., 2017; Tobler et al., 2015). Calcite has been observed to nucleate directly from aqueous solution at low saturation states, while at higher saturation states, calcite crystallization is preceded by the formation of amorphous calcium carbonate (ACC) and vaterite (Bots et al., 2012; Dietzel et al., 2020; Rodriguez-Blanco et al., 2011; Tobler et al., 2015, 2014). 
Differences in nucleation mechanisms affect the morphology and crystallinity of the precipitated phases, thereby affecting the reactivity of siderite in natural environments. Synthetic siderite is notably more reactive than natural siderite (Guo et al., 2010). A difference in nucleation mechanism at low versus high aqueous fluid saturation states could potentially account for some of these observed differences. Hence, in this study we assess the effect of the aqueous fluid saturation state on the nucleation rates and mechanisms of siderite through a series of turbidity experiments and batch experiments.

\section{METHODS}

\subsection{Thermodynamic calculations}

The saturation indices and ion activation products of all experimental fluids, as well as the dissolved carbon concentration in some experiments were computed with PHREEQC v.3 (Parkhurst and Appelo, 2013) together with its CarbFix database (Voigt et al., 2018). The ion activation product is defined as the product of the measured aqueous activities of the reaction products. For example, the ion activation product $(I A P)$ of siderite is defined as:

$$
I A P=a_{F e^{2+}} a_{C O_{3}^{2-}}
$$

Eq.1

where $a$ represents the activity of the subscripted aqueous species. Note that in natural systems the $I A P$ of siderite can be affected by the activity of other species including $\mathrm{Mg}$ and $\mathrm{Mn}$, which can co-precipitate in the siderite structure. The saturation index $(S I)$ is defined as:

$$
S I=\log \left(\frac{I A P}{K_{S P}}\right)
$$

where $K_{s p}$ represents the solubility constant of the mineral phase.

To assess the thermodynamic stability of potentially forming amorphous ferrous carbonates, two amorphous ferrous carbonates $(\mathrm{AFC}), \mathrm{Fe}\left(\mathrm{CO}_{3}\right)_{0.7}(\mathrm{OH})_{0.6}$ and $\mathrm{Fe}\left(\mathrm{CO}_{3}\right)_{0.5} \mathrm{OH}$, were added to 
the CarbFix database. The solubility constants of these phases were reported by Jiang and Tosca (2019) and Dideriksen et al. (2015), respectively. Additionally, the mineral chukanovite $\left(\mathrm{Fe}_{2} \mathrm{CO}_{3}(\mathrm{OH})_{2}\right)$ was added to the database, according to the solubility constant proposed by Azoulay et al., (2012).

\subsection{Turbidity experiments}

Turbidity experiments were performed in a COY glovebox containing a $4 \% \mathrm{H}_{2}, 10 \% \mathrm{CO}_{2}$ and $86 \% \mathrm{~N}_{2}$ atmosphere. The addition of $\mathrm{CO}_{2}$ to the glovebox atmosphere allowed for higher dissolved aqueous $\mathrm{C}$ concentrations, facilitating siderite precipitation. To prevent the oxidation of the reactive aqueous solutions and precipitates, all materials and aqueous solutions were equilibrated with the glovebox atmosphere for 48 hours to remove trace oxygen. Stock solutions of aqueous 1.5 $\mathrm{M} \mathrm{NaHCO}_{3}$ (Sigma-Aldrich) and 1.5 $\mathrm{M} \mathrm{FeCl}_{2} \bullet 4 \mathrm{H}_{2} \mathrm{O}$ (Sigma-Aldrich, Reagent Grade) were prepared with deoxygenated ultrapure water, following the method of Dideriksen et al. (2015). Aqueous solutions containing equimolar concentrations of $\mathrm{HCO}_{3}{ }^{-}$and $\mathrm{Fe}^{2+}$ ranging from of $18-80 \mathrm{mM}$ were prepared freshly at the start of each experiment. As the experimental solutions of these experiments were prepared in direct contact with the glovebox atmosphere, the dissolved aqueous $\mathrm{C}$ concentrations rapidly evolved over time to be in equilibrium with its coexisting gas phase. To account for the exchange of aqueous $\mathrm{C}$ with the coexisting gas phase, the aqueous $\mathrm{C}$ concentrations of the experiments were computed using PHREEQC v.3 (Parkhurst and Appelo, 2013). Note that the final $\mathrm{C}$ concentrations in the reactive aqueous solutions were higher than the $\mathrm{Fe}^{2+}$ concentration due to $\mathrm{C}$ input from the glovebox atmosphere (see Table 1). All experiments were performed at temperatures ranging between $22-23{ }^{\circ} \mathrm{C}$. A detailed 
description of the potential effect of such small temperatures variations on nucleation rates can be found in appendix A.

Turbidity was measured in $5 \mathrm{~mL}$ polystyrene cuvettes (dimensions $=10 \times 10 \times 50 \mathrm{~mm}$ ), which were placed in a AvaLight-DH-S-BAL light source spectrophotometer fitted with an Ocean Insight STS UV-Vis spectrometer and having a spot size of $25 \mu \mathrm{m}$. After adding the initial reactive aqueous solution to the cuvette, the cuvettes were sealed to prevent gas exchange with the glovebox atmosphere and the absorbance was measured at 20 seconds intervals at a wavelength of $420 \mathrm{~nm}$. The reactive solution in the cuvette was constantly stirred at $300 \mathrm{rpm}$ using a magnetic stirring plate.

Nucleation rates and induction times were computed from the UV-Vis measurements using the Johnson-Mehl-Avrami-Kolmogorov (JMAK) model (Avrami, 1940; Kolmogorov, 1937; William and Mehl, 1939), which is based on the Avrami equation:

$\alpha=1-e^{-(k(t-I))^{n}}$ Eq. 3 where $\alpha$ represents the degree of the reaction, $t$ denotes the elapsed time, $k$ designates a reaction constant, proportional to the nucleation rate, $I$ refers to the induction time and $n$ signifies the Avrami constant. The Avrami constant equals $n=1+d$, where $d$ represents the growth dimensionality. In this study the degree of reaction was computed form the absorbance data, such that the maximum absorbance in each experiment was normalized to 1 . To identify how turbidity is affected by the identity of the nucleating phase, solids were collected at preselected times, corresponding to different stages in the absorption spectra for further analysis.

Solids were collected from the turbidity experiments by centrifuging the contents of each cuvette in the glove box at $4000 \mathrm{~g}$ and discarding the overlying fluid. The solids were then washed three times by resuspending these in deoxygenated ethanol, centrifuging the samples and discarding the overlying fluid. The resulting solids were stored in deoxygenated ethanol inside 
the glovebox and dried just before analyses. X-ray diffraction (XRD) patterns of the solids were obtained using a Bruker D8 Discover. The samples were mounted on a silicone plate, capped with a polymer hemisphere and immediately measured. The spectra were background corrected by subtracting the spectra of the polymer hemisphere. Samples for Scanning Electron Microscopic (SEM) analysis were prepared in the glovebox and transported in a desiccator to prevent oxygenation. The samples were imaged with an EVO Ma10.

Table 1. Initial concentrations of $\mathrm{Fe}$ and calculated initial $\mathrm{C}$ concentrations at the onset of each turbidity experiment. Also included are the calculated saturation states of the fluid phase with respect to selected solids. The computed $\mathrm{pH}$ of the aqueous fluids is in close agreement to that measured in the initial aqueous fluids in the batch experiments (Table 2). The superscript 1 and 2 represent the amorphous ferrous carbonate phases as defined by Dideriksen et al. (2015) and Jiang and Tosca (2019): $\left(\mathrm{Fe}\left(\mathrm{CO}_{3}\right)_{0.7}(\mathrm{OH})_{0.6}\right)$ and $\left(\mathrm{Fe}\left(\mathrm{CO}_{3}\right)_{0.5} \mathrm{OH}\right)$, respectively. The table also shows the results of the fits of the turbidity data, using the JMAK model, an example of such a fit can be found in Figure 2. The $k$ and $I$ values computed for the duplicate experiments are provided in Table A.1.

\begin{tabular}{|c|c|c|c|c|c|c|c|c|c|c|c|}
\hline \multirow{2}{*}{$\begin{array}{l}\text { Experimental } \\
\text { name }\end{array}$} & \multirow[t]{2}{*}{$p H$} & \multirow{2}{*}{$\begin{array}{l}{[\mathrm{Fe}]} \\
(m M)\end{array}$} & \multirow{2}{*}{$\begin{array}{l}{[\mathrm{C}]} \\
(\mathrm{mM})\end{array}$} & \multirow{2}{*}{$\begin{array}{l}I A P \\
A F C^{1}\end{array}$} & \multirow{2}{*}{$\begin{array}{l}I A P \\
A F C^{2}\end{array}$} & \multirow{2}{*}{$\begin{array}{l}\text { SI } \\
\text { siderite }\end{array}$} & \multirow{2}{*}{$\begin{array}{l}\text { SI } \\
\text { chukanovite }\end{array}$} & \multirow{2}{*}{$\begin{array}{l}k^{*} \\
\left(\min ^{-1}\right)\end{array}$} & \multicolumn{3}{|c|}{$\boldsymbol{I}^{\dot{t}}$} \\
\hline & & & & & & & & & $\begin{array}{l}\text { Standard } \\
\text { error } k\end{array}$ & (min) & $\begin{array}{l}\text { Standard } \\
\text { error I }\end{array}$ \\
\hline T-18 & 6.04 & 18.90 & 43.10 & -2.78 & 0.877 & 2.78 & -0.313 & 0.01567 & $1.13 \times 10^{-4}$ & 5.76 & 2.96 \\
\hline T-23 & 6.16 & 23.65 & 48.40 & -2.47 & 1.18 & 3.08 & 0.296 & 0.03262 & $1.98 \times 10^{-4}$ & 0.426 & 0.356 \\
\hline T-28 & 6.25 & 28.16 & 53.47 & -2.24 & 1.41 & 3.31 & 0.750 & 0.05635 & $5.64 \times 10^{-4}$ & $\begin{array}{l}2.44 \times 10^{-} \\
-16\end{array}$ & 0 \\
\hline T-35 & 6.32 & 35.39 & 58.85 & -2.02 & 1.63 & 3.53 & 1.19 & 0.06172 & $1.35 \times 10^{-3}$ & $\begin{array}{l}4.33 \times 10^{-} \\
15\end{array}$ & 0 \\
\hline T-40 & 6.38 & 39.42 & 64.22 & -1.87 & 1.79 & 3.69 & 1.51 & & & & \\
\hline T-50 & 6.43 & 49.60 & 69.38 & -1.69 & 1.96 & 3.86 & 1.85 & & & & \\
\hline T-57 & 6.52 & 57.47 & 79.94 & -1.47 & 2.18 & 4.08 & 2.30 & & & & \\
\hline
\end{tabular}




\subsection{Batch experiments}

Further insight into siderite nucleation pathways was obtained from two series of batch experiments. One series was performed in reactive aqueous fluids containing initial $\mathrm{Fe}^{2+}$ and $\mathrm{C}$ concentrations of $35 \mathrm{mM}$ and $57 \mathrm{mM}$ respectively. This series is referred to as B-35. A second series was performed in reactive aqueous fluids with initial $\mathrm{Fe}^{2+}$ and total $\mathrm{C}$ concentrations of 57 $\mathrm{mM}$ and $80 \mathrm{mM}$ respectively. This series is referred to as B-57. The aqueous solution compositions and computed saturation indexes, with respect to selected phases during these experiments, can be found in Tables 2 and 3. The ionic strength of the reactive aqueous fluid phase was maintained at $0.15 \mathrm{Eq} / \mathrm{kgs}$ by adding reagent grade $\mathrm{NaCl}$ to these solutions, while the $\mathrm{pH}$ depended on the initial aqueous $\mathrm{C}$ concentration. The reactive aqueous fluids were equally divided into $60 \mathrm{~mL}$ Pyrex closed system reactors, which were then crimp sealed to prevent gas exchange with the glovebox atmosphere. The aqueous solutions were continuously stirred at 250 rpm on a magnetic stir plate. At preselected times one reactor in each of the series was opened. The particles were allowed to settle for 30 minutes prior to fluid sample collection to prevent sampling of the precipitated particles. Reactive fluid samples were collected and filtered through a $10 \mu \mathrm{m}$ nylon syringe filter. Methods of solid sample collection and preparation for X-ray diffraction (XRD) and Scanning Electron Microscope (SEM) analyses are the same as for the turbidity experiments described above.

From the SEM images it appeared that the size of the formed solid clusters and particles increased over time. To quantify the extent of particle growth, particle size was measured using ImageJ software. For each sample, one image was selected in which 8-12 particles were measured by visually defining the outer edges of each particle. An example of such 
measurements is given in Figure A.2. After all measurements were complete, the average was computed as well as the standard deviation (see Figures 3D \& 4D).

Table 2. Compositions of reactive aqueous fluids sampled from the B-35 batch experiments. The total dissolved carbon concentration, the IAP of the AFC phases, and the saturation index of siderite and chukanovite, were computed using PHREEQC, assuming the aqueous fluid was in equilibrium with the glovebox atmosphere. The superscript 1 and 2 represent the amorphous ferrous carbonate phases as defined by Dideriksen et al. $(2015)\left(\mathrm{Fe}\left(\mathrm{CO}_{3}\right)_{0.7}(\mathrm{OH})_{0.6}\right)$ and Tosca et al. (2019) $\left(\mathrm{Fe}\left(\mathrm{CO}_{3}\right)_{0.5} \mathrm{OH}\right)$ respectively.

\begin{tabular}{|c|c|c|c|c|c|c|c|}
\hline Time (h) & $p H$ & {$[\mathrm{Fe}](m M)$} & {$[C](m M)$} & $I A P A F C^{I}$ & $I A P A F C^{2}$ & SI siderite & SI chukanovite \\
\hline 0 & 6.37 & 35.41 & 59.00 & 2.20 & -2.44 & 3.59 & 1.35 \\
\hline 16.5 & 6.31 & 18.31 & 63.25 & 1.88 & -2.78 & 3.30 & 0.68 \\
\hline 22.5 & 6.21 & 13.76 & 52.55 & 1.55 & -3.09 & 2.96 & 0.05 \\
\hline 39.7 & 6.18 & 13.18 & 52.08 & 1.49 & -3.16 & 2.90 & -0.09 \\
\hline 64.0 & 6.1 & 11.70 & 50.87 & 1.30 & -3.35 & 2.72 & -0.48 \\
\hline 87.6 & 6.13 & 11.16 & 46.37 & 1.30 & -3.34 & 2.71 & -0.44 \\
\hline 111 & 6.11 & 11.35 & 48.54 & 1.29 & -3.36 & 2.70 & -0.48 \\
\hline 140 & 6.12 & 8.98 & 36.87 & 1.14 & -3.49 & 2.51 & -0.74 \\
\hline
\end{tabular}

Table 3. Compositions of reactive aqueous fluids sampled from the B-55 batch experiments. The total dissolved $\mathrm{C}$ concentration, the IAP of the AFC phases, and the saturation index of the siderite and chukanovite, were computed using PHREEQC, assuming the aqueous fluid was in equilibrium with the glovebox atmosphere. The superscript 1 and 2 repsresent the amorphous ferrous carbonate phases as defined by Dideriksen et al. (2015) $\left(\mathrm{Fe}\left(\mathrm{CO}_{3}\right)_{0.7}(\mathrm{OH})_{0.6}\right)$ and Tosca et al. (2019) $\left(\mathrm{Fe}\left(\mathrm{CO}_{3}\right)_{0.5} \mathrm{OH}\right)$ respectively.

\begin{tabular}{|c|c|c|c|c|c|c|c|}
\hline Time (h) & $p H$ & {$[\mathrm{Fe}](m M)$} & {$[\mathrm{C}](\boldsymbol{m} M)$} & $I A P A F C^{I}$ & $I A P A F C^{2}$ & SI siderite & SI chukanovite \\
\hline 0 & 6.53 & 57.72 & 80.38 & 2.68 & -1.96 & 4.08 & 2.30 \\
\hline 0.100 & 6.48 & 12.58 & 34.98 & 1.79 & -2.79 & 3.10 & 0.65 \\
\hline 0.500 & 6.39 & 11.01 & 32.95 & 1.58 & -3.01 & 2.90 & 0.22 \\
\hline 1.25 & 6.28 & 14.55 & 50.34 & 1.64 & -2.99 & 3.03 & 0.25 \\
\hline 6.10 & 6.22 & 16.59 & 62.09 & 1.66 & -3.00 & 3.08 & 0.23 \\
\hline 24.0 & 6.21 & 8.29 & 29.14 & 1.14 & -3.45 & 2.47 & -0.67 \\
\hline 38.0 & 6.22 & 4.86 & 14.77 & 0.74 & -3.80 & 1.98 & -1.36 \\
\hline 61.9 & 6.18 & 4.75 & 15.06 & 0.67 & -3.87 & 1.92 & -1.51 \\
\hline 107 & 6.2 & 4.26 & 12.61 & 0.60 & -3.92 & 1.83 & -1.61 \\
\hline
\end{tabular}


2.4. Fe measurements 
Aqueous $\mathrm{Fe}^{2+}$ concentrations were quantified using the colorimetric ferrozine method, following a method adapted from Viollier et al., (2000). For this method two reagents were prepared: a ferrozine reagent, containing $6.17 \mathrm{mM}$ ferrozine in $4.14 \mathrm{M}$ aqueous Na-acetate and a reducing agent containing 1.4 M hydroxylamine- $\mathrm{HCl}$ in $2 \mathrm{M}$ aqueous $\mathrm{HCl} .2 \mathrm{~mL}$ of the aqueous sample or calibration standard and $500 \mu \mathrm{L}$ of ferrozine reagent was added to a $5 \mathrm{~mL}$ cuvette. The sample absorbance was immediately measured at a wavelength of $562 \mathrm{~nm}$ via UV-Vis spectroscopy as described in section 3.1. This first measurement quantifies the aqueous $\mathrm{Fe}^{2+}$ concentration. Directly after this measurement, $300 \mu \mathrm{L}$ of the reducing agent was added to the sample/ferrozine mixture in the cuvette. After 10-minutes the complete reduction of any $\mathrm{Fe}^{3+}$ in solution was attained. The absorbance at $562 \mathrm{~nm}$ was then measured again to quantify the total $\mathrm{Fe}\left(\mathrm{Fe}^{2+}+\mathrm{Fe}^{3+}\right)$ concentration in the fluid. The standard deviation of repeated (RDS) measurements was $1.4 \%$

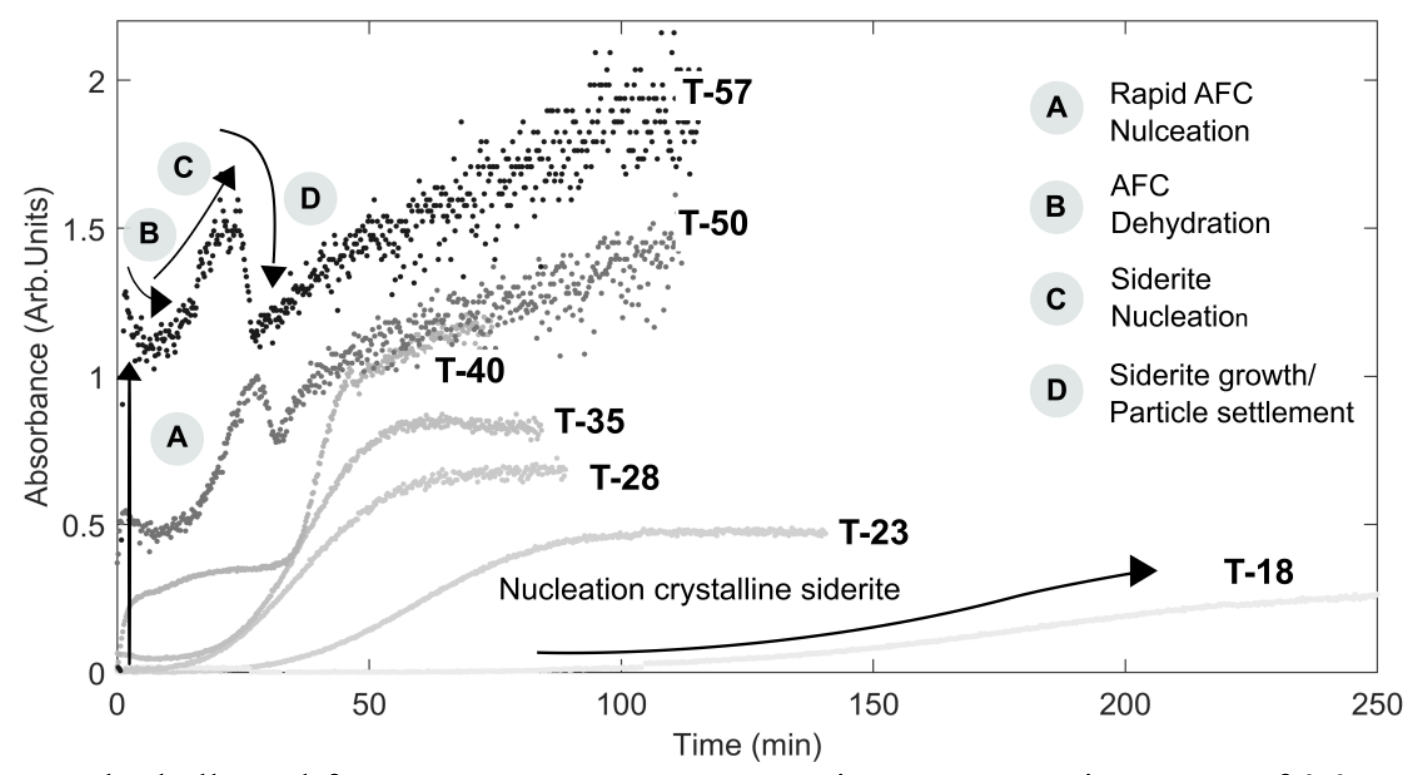

and the method allowed for aqueous Fe measurements in a concentration range of 0.05 to $2 \mathrm{mM}$ aqueous $\mathrm{Fe}^{2+}$.

Figure 1. UV-Vis spectra of turbidity experiments measured at $420 \mathrm{~nm}$. The labels correspond to the experiment name given in Table 1 . Note that as the initial reactive aqueous fluid 
concentrations increase, the temporal evolution of the turbidity profile changes. An interpretation on the mechanisms affecting the solution turbidity is provided in the figure. 


\section{RESULTS AND DISCUSSION}

\subsection{Turbidity experiments}

Figure 1 illustrates the temporal turbidity profiles of the reacted fluids for various experiments performed in this study. The turbidity profiles are affected by the $\mathrm{Fe}^{2+}$ and $\mathrm{C}$ concentrations of the initial reactive aqueous solutions. Such changes can be attributed to the nucleation rate, the number of nuclei formed, and the nucleation sequence. The increase in slope and maximum turbidity as the initial reactive fluid saturation index increases are interpreted to represent, respectively, an increase in the nucleation rate and the number of nuclei formed (Montanari et al., 2017; Tobler et al., 2014, 2015; Wang et al., 2012). The change in the temporal evolution of the turbidity, observed for the T-18 to T-35 experiments, compared to T-40 to T-57 experiments is attributed to a change in the nucleation sequence.
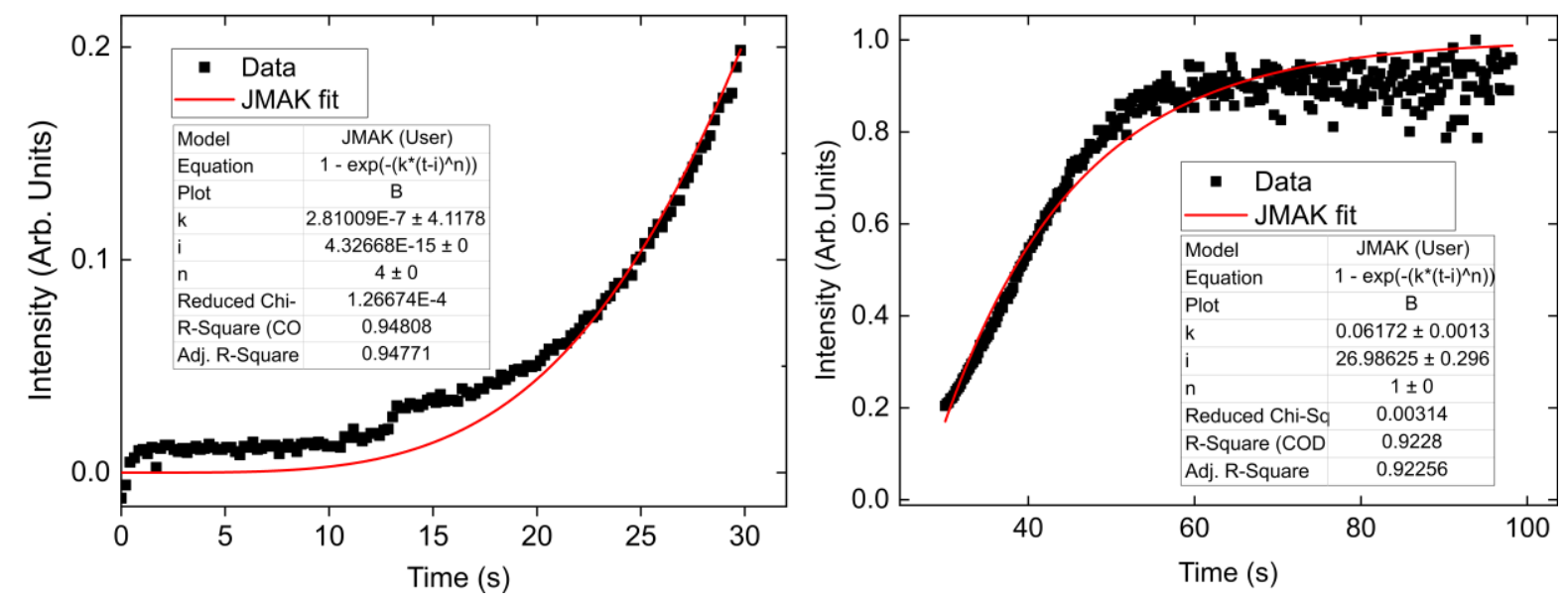

Figure 2. Representative fits of UV-Vis data collected from experiment T-35 (B). The plot on the left shows the fit of the data collected during the initial part of the turbidity experiment (using $n=4$ ), while the plot on the right shows the fit of the data collected during the latter part of the turbidity experiment (using $n=1$ ). The fit on the left is used to compute the nucleation incubation time $(I)$, while the fit on the right is used to determine the rate constant $(k)$. 
Changes in the nucleation rate as a function of initial reactive fluid saturation state can be further quantified using the JMAK model, as described by Eq. 3. A representative example of a fit of turbidity profile data fit to this equation is provided in Figure 2. The results summarized in Table 1 confirm that the nucleation rate increases, while the induction time decreases, as the initial reactor fluid $\mathrm{Fe}^{2+}$ and $\mathrm{C}$ concentrations increase. Note that the initial part of the graph is fitted using $n=1$, while the second part is fitted using $n=4$, suggesting that the initial nucleation is dominated by three-dimensional nucleation, while the second part is dominated by crystal growth, consistent with $n=1$. Significant differences in the incubation times and nucleation rates are observed in duplicate measurements (see Figure A.3 and Table A.1). These differences could result from the partial oxidation of aqueous $\mathrm{Fe}^{2+}$ by trace oxygen. Partial $\mathrm{Fe}^{2+}$ oxidation provokes the precipitation of $\mathrm{Fe}^{3+}$-hydroxides (Stumm and Lee, 1961), which could provide nucleation surfaces for siderite. The formation of such surfaces could significantly reduce the siderite nucleation barrier.

The changes in the turbidity profiles observed between the experiments performed in initial fluids with relatively low $\mathrm{Fe}^{2+}$ and $\mathrm{C}$ concentrations (experiments $\mathrm{T}-18$ to $\mathrm{T}-35$ ) compared to those performed in fluids having higher concentrations indicate a change in the siderite nucleation sequence. The gradual increase in the turbidity, observed in the experiments run with lower initial fluid concentrations, corresponds to a classical nucleation pathway with crystalline siderite precipitating directly from the aqueous solution. The formation of pre-nucleation clusters prior to the nucleation of crystalline siderite cannot be excluded based on this data. Precipitation of AFC phases is, however, thermodynamically unfavorable under these experimental conditions (see Table 1). The nucleation of crystalline siderite is verified by the XRD spectrum of the solids collected after 2 hours of reaction from experiment T-35 (Fig. 3B). SEM images, such as 
that shown in Fig. 3E, show this sample to consist of particles ranging from 281 to $319 \mathrm{~nm}$ in size. The angular shapes of the particles are indicative of crystalline siderite.

The siderite nucleation sequence from the higher concentration initial reactive fluids is more complex, as reflected by the temporal changes in the turbidity profile (Fig. 1). During the first few seconds of these experiments, the turbidity increases rapidly. This is interpreted to stem from the formation of amorphous iron carbonate (c.f. Tobler et al., 2015). XRD analyses of solids collected after 2 minutes of reaction from in the T-57 batch experiments, confirm the precipitation of an amorphous phase, although some chukanovite formed, as indicated by the small diffraction peak at $33.392 \theta$ (Fig. 4B). Equally, SEM images of this sample show that the precipitated nano-sized particles have no evident angular morphology (Fig. 4E). After the rapid initial increase in turbidity in this experiment, the turbidity decreased. Such a decrease has previously been observed during multi-step calcite nucleation turbidity experiments and has been attributed to the dehydration and recrystallization of the initially formed amorphous calcium carbonate (ACC) (Bots et al., 2012; Tobler et al., 2015). As the $\mathrm{Fe}^{2+}$ and total $\mathrm{C}$ concentrations of the reactive fluid decrease during an experiment, AFC precipitation becomes thermodynamically unfavorable, yet crystalline siderite could nucleate. Montes-Hernandez and Renard (2016) previously showed that the transformation of AFC to siderite can be attributed both to the dehydration and the recrystallization of the AFC phase. In Figure 1, siderite nucleation is evident from the increase in the turbidity after the initial turbidity decreases, suggesting the formation of new nuclei, consistent with trends observed during calcite crystallization upon initial ACC formation (Montanari et al., 2017; Tobler et al., 2014). Subsequent siderite growth leads to the settling of the formed particles, resulting in a decrease in 
the measured turbidity (Fig. 1). The formation of crystalline siderite is confirmed by XRD analyses of the solids collected after 2 hours from the T- 57 turbidity experiments (Fig. 4B).

A number of past studies have reported the spontaneous nucleation of AFC from concentrated-initial reactive fluids. Jiang and Tosca (2019) reported that spontaneous nucleation of AFC occurs when the ion activation product (IAP) of $\mathrm{Fe}\left(\mathrm{CO}_{3}\right)_{0.5}(\mathrm{OH})$ exceeds 2.20. Dideriksen et al., (2015) reported that the for the spontaneous nucleation of the AFC phase, $\mathrm{Fe}\left(\mathrm{CO}_{3}\right)_{0.7}(\mathrm{OH})_{0.6}$, IAP values need to exceed -1.95. From the Table 1, it is apparent that an initial $\mathrm{Fe}^{2+}$ concentration of $>35.39 \mathrm{mM}$ and $\mathrm{C}$ concentration of $>59 \mathrm{mM}$, spontaneous AFC nucleation is favorable as the $\mathrm{Fe}\left(\mathrm{CO}_{3}\right)_{0.7}(\mathrm{OH})_{0.6} I A P$ values are $\geq-1.87$, while at initial $\mathrm{Fe}^{2+}$ and C concentrations of $\leq 35.39 \mathrm{mM}$ and $\leq 58.85 \mathrm{mM}$ respectively the spontaneous nucleation of AFC is unfavorable.

\subsection{Batch experiments}

Further insight into the siderite nucleation can be obtained from the two series of batch experiments performed in initial aqueous $\mathrm{Fe}^{2+}$ and $\mathrm{C}$ concentrations of $35.39 \mathrm{mM}$ and $59 \mathrm{mM}$ (series B-35), and initial aqueous $\mathrm{Fe}^{2+}$ and $\mathrm{C}$ concentrations of $57 \mathrm{mM}$ and $80 \mathrm{mM}$ (series B-57). Results of these experiments are shown in Figures 3 and 4.

In the batch experiments B-35, run with initial reactive fluids containing $35.39 \mathrm{mM} \mathrm{Fe}^{2+}$ and $57 \mathrm{mM} \mathrm{C}$, chukanovite formed in addition to siderite, as shown by the XRD analyses of the solids (Fig. 3B). Chukanovite formation has been reported to be favored over siderite nucleation when the aqueous $\mathrm{Fe}^{2+}: \mathrm{C}$ ratio is lower than the ideal 1:1 ratio for siderite and when the $\mathrm{pH}$ of the solution is relatively high (Azoulay et al., 2012). At the onset of this experimental series both conditions are met. Over time, the contribution of chukanovite to the XRD spectrum decreases, 
suggesting that the initially formed chukanovite recrystallizes to siderite. Alternatively, it is possible that the relative contribution of chukanovite to the XRD pattern decreases as chukanovite growth stagnates while siderite growth persists throughout the experiment. The decreased contribution of the chukanovite to the total solid sample over time is consistent with the thermodynamic stability of chukanovite in Fe-carbonate systems. The $\mathrm{pH}$ and $\mathrm{Fe}^{2+}$ and $\mathrm{C}$ concentrations of the reactive fluids decrease over time during this batch experiment series as siderite and chukanovite precipitates. By the end of the longest duration batch experiment of series B-35, chukanovite is undersaturated (Table 2). Reactive fluid $\mathrm{Fe}^{2+}$ concentrations decrease during the B-35 experiments while the grain size of the formed particles increases with time. The increase in grain size over time during the early part of the experimental series (Fig. 3D) can be attributed to Ostwald ripening, which facilitates the crystallization and growth of formed particles to minimize the surface energy of the nuclei (Marqusee and Ross, 1984). Equally, numerical studies on calcite, kaolinite and amorphous silica precipitation showed that particle size depends on the saturation state of the reactive solutions (Fritz et al., 2013, 2009; Noguera et al., 2015). When the saturation state of the solution is high, the rapid precipitation of small particles is favorable, while at lower saturation states growth increasingly dominates over nucleation. After 45 hours of reaction, the particle size in experimental series B-35 slowly decreases. Such a decrease in the particle size of siderite has previously been observed by Montes-Hernandez and Renard (2016), who attributed this observation to a decrease in the porosity of their particles over time. 

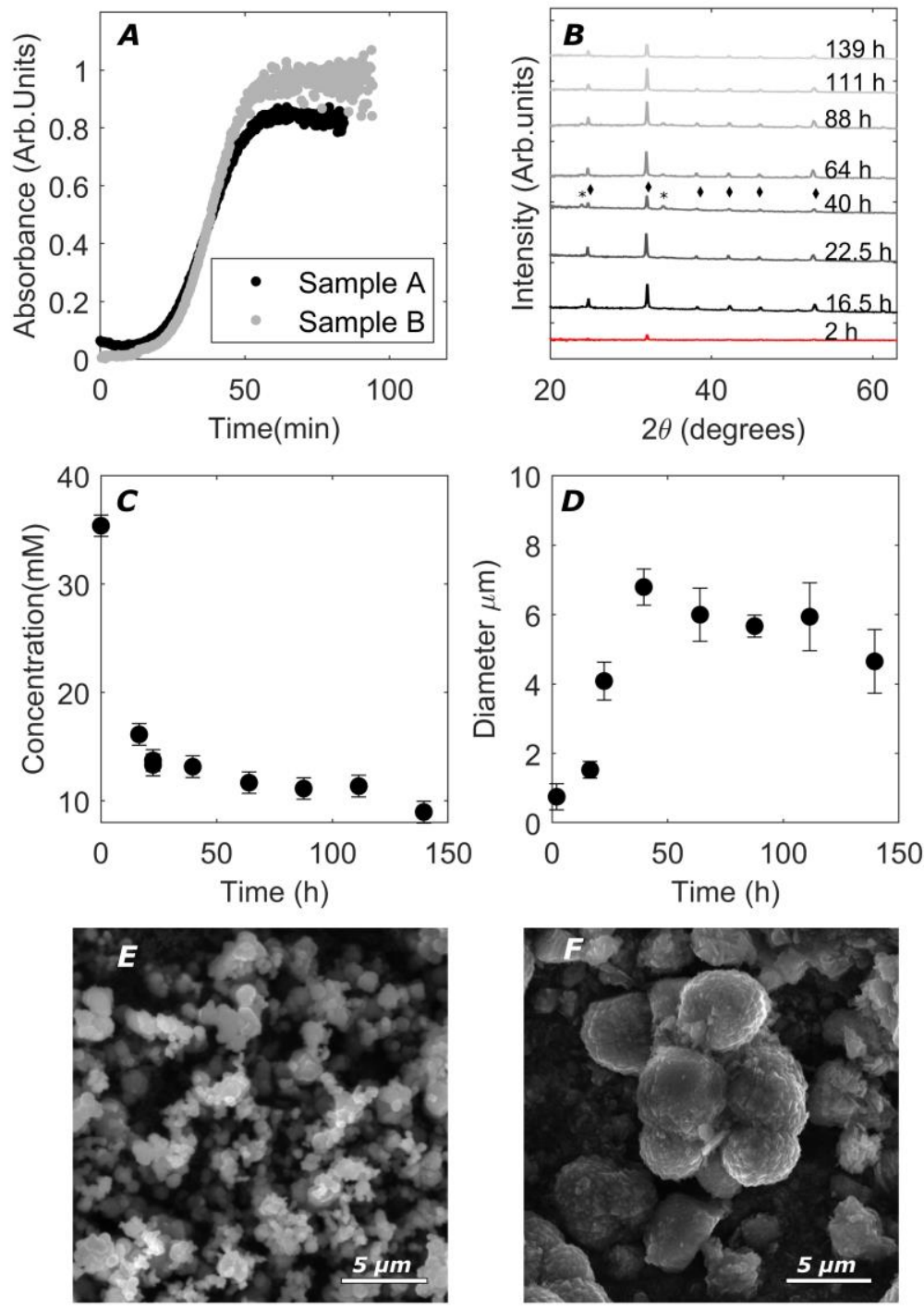

Figure 3. Results of turbidity and batch experiments B-35 performed in initial aqueous fluids containing $35.50 \mathrm{mM} \mathrm{Fe} \mathrm{e}^{2+}$ and $58.85 \mathrm{mM}$ aqueous $\mathrm{C}$. (A) The turbidity profile of two duplicate experiments, as previously shown in Figure 1. (B) XRD patterns of collected solids, where the $2 \mathrm{~h}$ solid sample was collected from the turbidity experiment, as indicated by the red color, while the other spectra are those collected from the solids obtained from the B-35 batch experiments. (C\&D) Aqueous Fe concentrations and the particle sizes obtained from these batch experiments over time. (E\&F) SEM images of the solids collected after $2 \mathrm{~h}$ from the turbity experiment and after $139 \mathrm{~h}$ from the batch experiment.

The morphology of the precipitated particles recovered from experiments B-35 ranges from rhombohedral to spherical. Spherical growth of siderite has been observed by Jiang and Tosca $(2019,2020)$ and Jimenez-Lopez and Romanek (2004). Spherical growth tends to occur at highly 
non-equilibrium conditions (Fletcher and Merino, 2001). As the aqueous $\mathrm{Fe}$ and $\mathrm{C}$ concentrations decrease, rhombohedral siderite formation becomes favored, as observed in Figure 3F. This variation in morphology is similar to that observed for calcite, where spherical calcite forms prior to the formation of rhombohedral calcite (Tracy et al., 1998). Over time, the spherical calcite recrystallizes to rhombohedral calcite. Equally, Jimenez-Lopez and Romanek (2004) observed the continuous aging of siderite over a year long period, with siderite becoming more rhombohedral over time.

Figure 5 indicates that in the B-35 samples collected after 17 hours some iron-oxy-hydroxides formed, as suggested by the needle like particles in some of the images (Schwertmann and Fischer, 1973; Fig. 5). Oxidation of a sub-set of this sample likely resulted from the presence of trace oxygen in the sampling tubes during sample collection. Oxidation, therefore, did not affect other samples nor did it result in oxidation of aqueous $\mathrm{Fe}^{2+}$ in the fluid samples. Solids collected from the B-35 batch experiment that ran 17 hours turned brownish in color upon sample collection, an indicator of sample oxidation (Dideriksen et al., 2015). Synthetic siderite is highly sensitive to oxidation and a trace amount of $\mathrm{O}_{2}$ in the glovebox could rapidly oxidize some of the precipitated nuclei (Dideriksen et al., 2015).

Figure 4 and Table 3 show the results of the B-57 batch experiments. These batch experiments were designed to provide further insight into the T-57 turbidity experiments. Note, however, that in the turbidity experiments, the change in turbidity suggests that siderite nuclei form after approximately 40 minutes, while in the batch experiments the first evidence of crystalline siderite is found in the XRD spectra of solids collected after 6 hours. This difference could result from the lower mixing rates in the batch experiments (see Fitchett and Tarbell, 1990; O'Grady et al., 2007). 
The temporal evolution of the XRD analyses (Fig. 4B), particle size changes (Fig. 4D) and the SEM images of the solids (Fig. 4F and 5) all confirm a multi-step nucleation sequence in the B57 experiments that differs from that of the B-35 experiments. The SEM images suggests that the formation siderite proceeds via the initial precipitation of $\mathrm{AFC}$, followed by dehydration and recrystallization to siderite, thereby preserving the spherical shape of the AFC phases. The rhombohedral growth patterns visible on top of the spherical particles are indicative for the directional growth of siderite mesocrystals, as previously observed by Montes-Hernandez and Renard (2016). XRD analyses indicate that chukanovite is more abundant in the B-57 experiments relative to the B-35 experiments (Fig. 3B \& 4B). The abundance of this phase in the solids is attributed to the higher initial $\mathrm{pH}$ of the $\mathrm{B}-57$ reactive aqueous solutions.

Further differences in the morphology between the precipitates formed during the B-57 experiments compared to the B-35 experiments are evident from the SEM analysis (Fig. 3F, Fig. 4F \& Fig. 5). In the B-57 experiments, the particles appear more spherical and radial growth patterns are apparent (see Fig. 5). The dominance of radial growth patterns at higher initial Fe and $\mathrm{C}$ concentration experiments suggests that radial growth dominates at far from equilibrium conditions. Furthermore, Figure 4F shows that some particles look like shards or flakes, as indicated by a star in this figure. From the XRD analyses, one might expect these shards to be chukanovite, but previous studies found chukanovite grows in needle-like, acicular or fibrous structures (Pandarinathan et al., 2014; Pekov et al., 2007). These shards could therefore have formed as a result of templated growth on the glass reactor bottles. During the experiments, a layer of precipitate formed on the glass walls, which was scraped off during sample collection. Such templated growth has previously been observed during aragonite, calcite and lead sulfide growth (Heywood and Mann, 1994). Alternatively, the morphology of this precipitate could 
result from sample preparation. Dideriksen et al. (2015) showed that siderite grains can be crushed during sample preparation, leading to the formation of 'shard'-like morphologies.
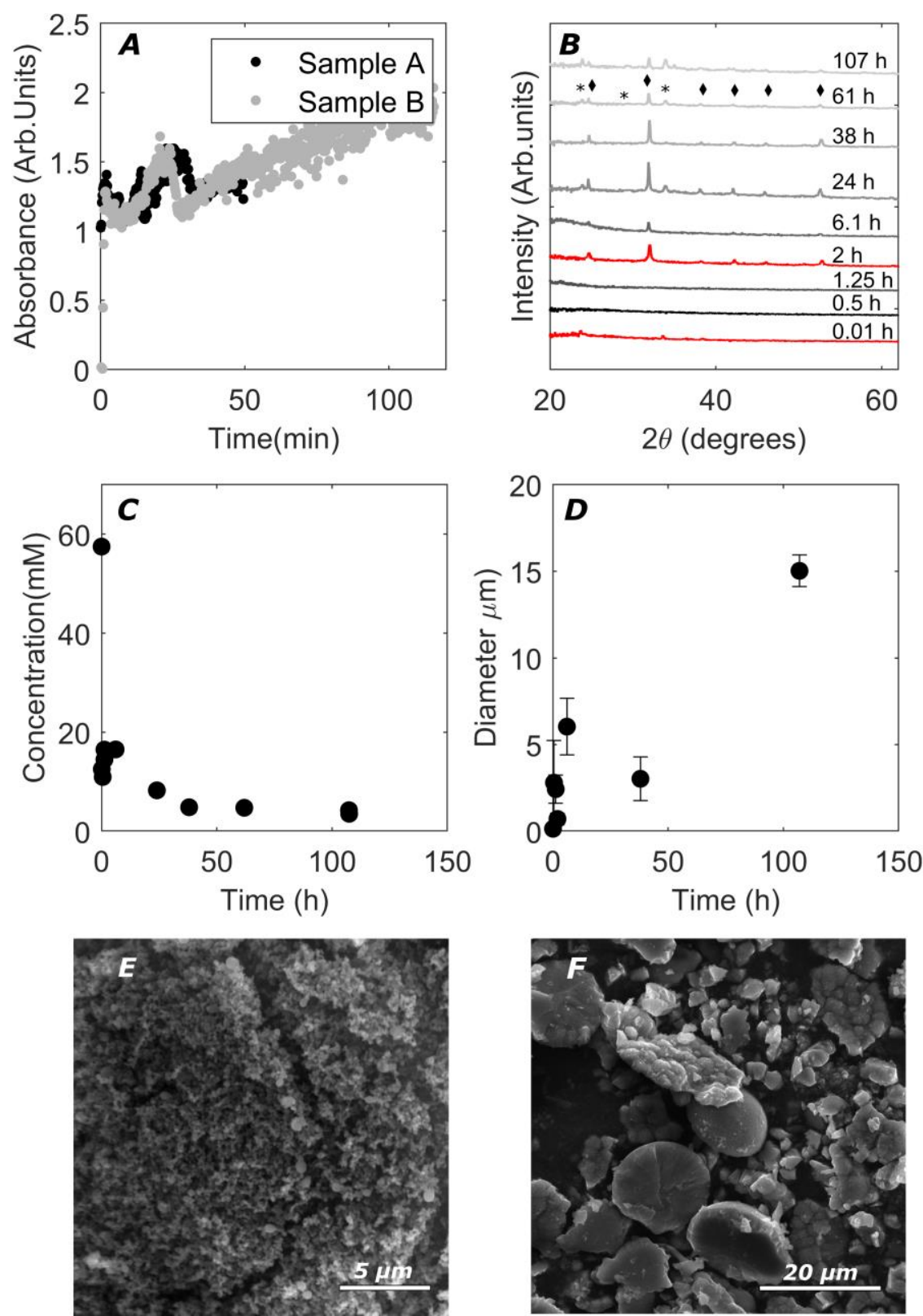

Figure 4. Results of the T-55 and B-57 experiments. (A) The turbidity profile of two duplicate samples. (B) XRD spectra of collected solids, where the $0.01 \mathrm{~h}$ and $2 \mathrm{~h}$ sample was collected from the turbidity experiment, while the other spectra are of the solids collected from the batch experiments. (C\&D) show the aqueous Fe concentration and the particle size over time, obtained from the batch experiments. (E\&F) SEM images of the $0.01 \mathrm{~h}$ sample collected from the turbity experiment and the $139 \mathrm{~h}$ sample collected from the batch experiment. 

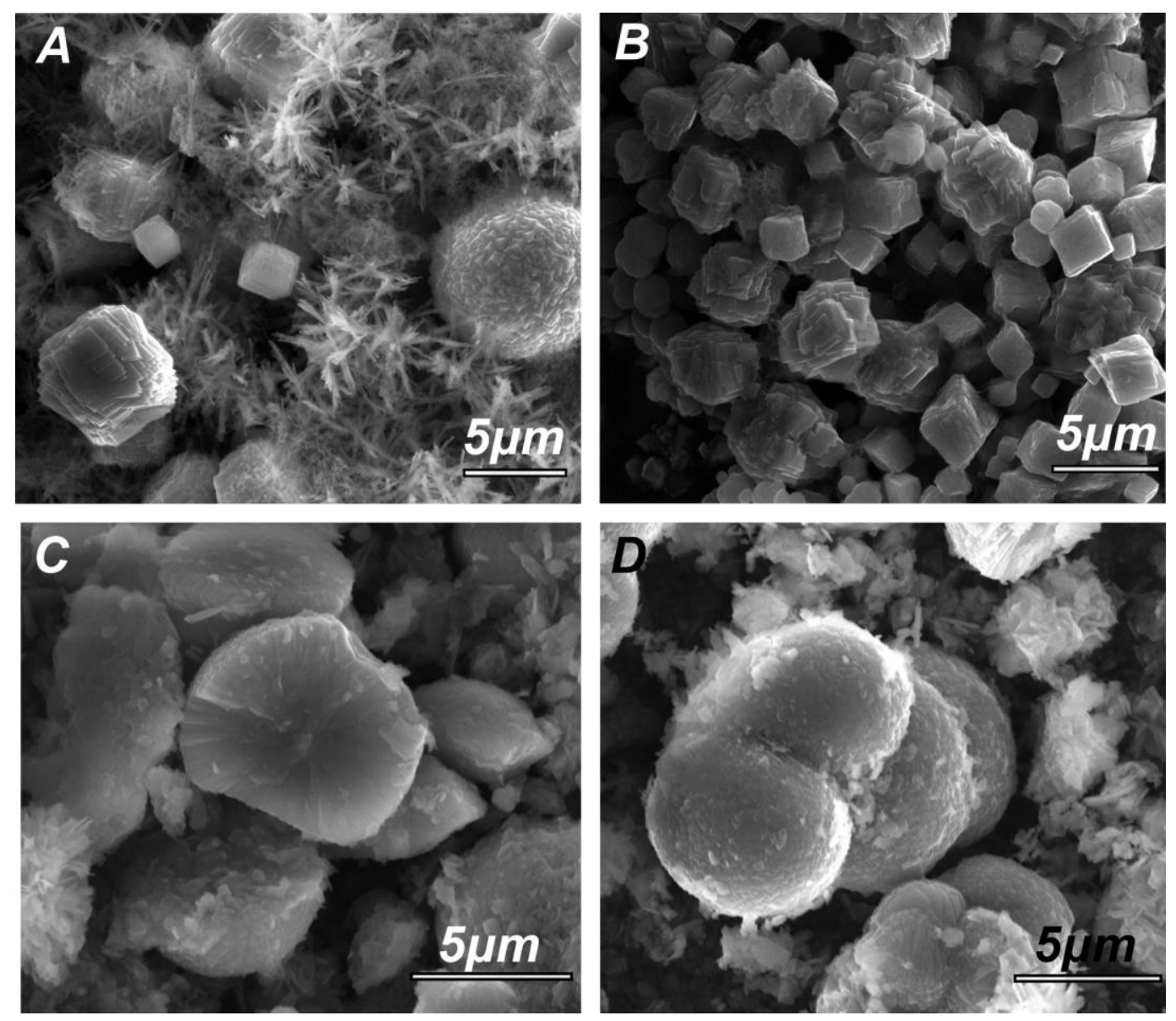

Figure 5. SEM images of sample B-35 (Image A and B) and B-57 (Image C and D). The samples in A and B were collected after 17 and 60 hours of reaction respectively. The samples in $\mathrm{C}$ and $\mathrm{D}$ were collected after 6 and 60 hours of reaction respectively. Note that the particles collected from the B-35 experiment are notably more rhombohedral compared to the those collected from the B-57 experiment, which are more spherical. The difference in morphology is interpreted to result from the difference in the saturation state of their respective reactive fluids.

\subsection{Implications for natural siderite reactivity and isotopic signatures}

From the batch and turbidity experiments it is evident that the initial reactive fluid saturation state affects the siderite nucleation sequence, where crystalline siderite forms directly from aqueous solution at lower supersaturation, while at higher supersaturation states precipitation proceeds via the initial nucleation of AFC followed by its recrystallization and dehydration to 
form siderite (Montes-Hernandez and Renard, 2016). Such changes in the nucleation mechanism can affect the reactivity of siderite as well as the isotopic signature of the precipitated material.

The reactivity and growth rates of minerals are proportional to the reactive surface area available for the aqueous solution interaction (c.f. Gautier et al., 2001; Schott et al., 2012). The number of active surface sites depends on the morphology and porosity of the formed mineral, where minerals with a high degree of surface roughness and high porosity are more reactive compared to minerals with relatively less surface roughness and comparatively little porosity (c.f. Gautier et al., 2001; Schott et al., 2012). Nucleation at high solution saturation states is characterized by the initial precipitation of AFC. This subsequently results in the formation of spherical siderite, with a high degree of surface roughness and a porous structure (Jiang and Tosca, 2019, 2020; Jimenez-Lopez and Romanek, 2004; Montes-Hernandez and Renard, 2016), while precipitation of siderite at low saturation states is characterized by more rhombohedral particles with lower surface roughness (Fig. 3F \& 4F). This difference in morphology is most apparent in the Figure 5, which indicates that after $60 \mathrm{~h}$, the particles formed in the B-35 experiments are rhombohedral, while the precipitates in the experiment B-57 are spherical. The rhombohedral particles formed during the B-35 experiment resemble natural siderite, which is rhombohedral in shape and has smooth surfaces (c.f. Bénézeth et al., 2009). The high degree of surface roughness and spherical morphology of synthetic siderite initially precipitated at high degrees of supersaturation results a relatively high number of the actives surface sites. Hence, siderite synthesized at high degrees of supersaturation is more reactive compared to natural siderite or siderite synthesized at lower degrees of aqueous supersaturation. Guo et al. (2007, 2010) showed that synthetic siderite, synthesized from a highly supersaturated aqueous $1 \mathrm{M} \mathrm{Fe}^{2+}$ and $2 \mathrm{M} \mathrm{HCO}_{3}{ }^{-}$solution, is more affective at removing arsenic from contaminated solutions 
compared to natural siderite. Although synthetic siderite precipitated from highly supersaturated solutions is more effective at remediating As contamination, the extrapolation of results obtained for synthetic siderites to natural siderite environments could result in an overestimation of the reactivity or growth rates of siderite in such systems. It might thus be more appropriate to study the reactivity and growth rates of siderite nucleated at lower saturation states, more closely resembling the siderite and aqueous conditions found in natural environments.

Differences in nucleation mechanism and mineral growth rates also need to be considered to correctly interpret the isotopic signatures of siderite in geological records. The isotopic $\delta^{18} \mathrm{O}$ and $\delta^{13} \mathrm{C}$ signatures recorded in siderite have been used to determine paleo depositional environments and formation conditions (c.f. El Albani et al., 2001; Huggett et al., 2010; Matsumoto, 1989; Mortimer and Coleman, 1997; Sapota et al., 2006). More recently, clumped isotope analyses on siderite samples has been employed to determine the paleoclimate conditions during siderite deposition (Fernandez et al., 2014). Mavromatis et al. (2013) and Purgstaller et al. (2016) showed that in Mg-bearing calcite, the extent of isotopic fractionation depends on the nucleation mechanism and mineral growth rate. The $\mathrm{Mg}$ and $\mathrm{Ca}$ isotope compositions are considerably lighter in calcite crystallized via ACC, compared to calcite directly crystallized from aqueous solution (Purgstaller et al., 2016). Equally, the $\delta^{18} \mathrm{O}$ values in Mg-rich calcite are affected by their nucleation/growth pathway. The $\delta^{18} \mathrm{O}$ fractionation between the reactive aqueous solution and the precipitate is higher in Mg-calcites nucleated via an amorphous precursor compared Mgcalcites that followed a classical nucleation pathway (Dietzel et al., 2020). The isotopic signature of siderite could be similarly affected by differences the nucleation pathways and thus the degree of aqueous fluid supersaturation. Hence, the accurate interpretation of isotopic $\delta^{18} \mathrm{O}$ and $\delta^{13} \mathrm{C}$ signatures requires insights in aqueous saturation states during the time of siderite formation. 


\section{CONCLUSION}

The nucleation sequence of siderite depends on the saturation state of siderite of its originating aqueous solution. XRD analyses and turbidity measurements of experiments at initial siderite saturation states $>3.53$ indicate that siderite crystalizes from initially precipitated AFC phases. In initial solutions with a siderite $S I$ of $\leq 3.53$, nucleation proceeds via the direct formation of siderite from aqueous solution. This is the first study to report the direct nucleation of siderite from aqueous solution. The difference in siderite nucleation sequence as a function of aqueous saturation states likely affects both the reactivity of the synthesized material as well as the isotopic signature of the precipitated siderite.

\section{Funding Sources}

This project has received funding from the European Union's Horizon 2020 research and innovation programme under the Marie Skłodowska-Curie grant agreement No 675219.

\section{ACKNOWLEDGMENT}

We would like to thank Marco Mangayayam and Adrian Schiefler for their support in the laboratory, without them we could not have performed these experiments. Furthermore, we would like to acknowledge Henning O. Sørensen for his help on the SEM.

\section{REFERENCES}

Avrami, M., 1940. Kinetics of phase change. II transformation-time relations for random 
distribution of nuclei. J. Chem. Phys. 8, 212-224.

Azoulay, I., Rémazeilles, C., Refait, P., 2012. Determination of standard Gibbs free energy of formation of chukanovite and Pourbaix diagrams of iron in carbonated media. Corros. Sci. https://doi.org/10.1016/j.corsci.2012.01.033

Bénézeth, P., Dandurand, J., Harrichoury, J., 2009. Solubility product of siderite $\left(\mathrm{FeCO}_{3}\right)$ as a function of temperature $\left(25-250 \quad{ }^{\circ} \mathrm{C}\right) . \quad$ Chem. Geol. 265, 3-12. https://doi.org/10.1016/j.chemgeo.2009.03.015

Bots, P., Benning, L.G., Rodriguez-Blanco, J.-D., Roncal-Herrero, T., Shaw, S., 2012. Mechanistic Insights into the Crystallization of Amorphous Calcium Carbonate (ACC). Cryst. Growth Des. 12, 3806-3814. https://doi.org/10.1021/cg300676b

Bouzenoune, A., Lécolle, P., 1997. Petrographic and geochemical arguments for hydrothermal formation of the Ouenza siderite deposit (NE Algeria). Miner. Depos. 32, 189-196. https://doi.org/10.1007/s001260050084

Chovan, M., Ozdin, D., 2003. Chemical composition of Ni, Co and Fe sulphoarsenides and arsenides in the hydrothermal siderite veins in the Western Carpathians (Slovakia). Miner. Sci. Carpathians, Miskolc, Hungary.

Dideriksen, K., Frandsen, C., Bovet, N., Wallace, A.F., Sel, O., Arbour, T., Navrotsky, A., De Yoreo, J.J., Banfield, J.F., 2015. Formation and transformation of a short range ordered iron carbonate precursor. Geochim. Cosmochim. Acta 164, 94-109. https://doi.org/10.1016/J.GCA.2015.05.005 
Dietzel, M., Purgstaller, B., Kluge, T., Leis, A., Mavromatis, V., 2020. Oxygen and clumped isotope fractionation during the formation of $\mathrm{Mg}$ calcite via an amorphous precursor. $\begin{array}{llll}\text { Geochim. } & \text { Cosmochim. }\end{array}$ https://doi.org/https://doi.org/10.1016/j.gca.2020.02.032

Duckworth, O.W., Martin, S.T., 2004. Role of molecular oxygen in the dissolution of siderite and rhodochrosite. Geochim. Cosmochim. Acta 68, 607-621. https://doi.org/10.1016/S0016-7037(03)00464-2

El Albani, A., Vachard, D., Kuhnt, W., Thurow, J., 2001. The role of diagenetic carbonate concretions in the preservation of the original sedimentary record. Sedimentology $48,875-$ 886.

Erdem, M., Gür, F., Tümen, F., 2004. Cr(VI) reduction in aqueous solutions by siderite. J. Hazard. Mater. 113, 217-222. https://doi.org/10.1016/J.JHAZMAT.2004.06.012

Erdem, M., Özverdi, A., 2005. Lead adsorption from aqueous solution onto siderite. Sep. Purif. Technol. 42, 259-264. https://doi.org/10.1016/J.SEPPUR.2004.08.004

Fernandez, A., Tang, J., Rosenheim, B.E., 2014. Siderite 'clumped' isotope thermometry: a new paleoclimate proxy for humid continental environments. Geochim. Cosmochim. Acta 126, $411-421$.

Fisher, Q.J., Raiswell, R., Marshall, J.D., 1998. Siderite concretions from nonmarine shales (Westphalian A) of the Pennines, England; controls on their growth and composition. J. Sediment. Res. 68, 1034-1045. 
Fitchett, D.E., Tarbell, J.M., 1990. Effect of mixing on the precipitation of barium sulfate in an MSMPR reactorssss. AIChE J. 36, 511-522.

Fletcher, R.C., Merino, E., 2001. Mineral growth in rocks: kinetic-rheological models of replacement, vein formation, and syntectonic crystallization. Geochim. Cosmochim. Acta 65, 3733-3748. https://doi.org/10.1016/S0016-7037(01)00726-8

Fritz, B., Clement, A., Amal, Y., Noguera, C., 2009. Simulation of the nucleation and growth of simple clay minerals in weathering processes: The NANOKIN code. Geochim. Cosmochim. Acta $73,1340-1358$.

Fritz, B., Clément, A., Montes-Hernandez, G., Noguera, C., 2013. Calcite formation by hydrothermal carbonation of portlandite: complementary insights from experiment and simulation. CrystEngComm 15, 3392-3401.

Gautier, J.-M., Oelkers, E.H., Schott, J., 2001. Are quartz dissolution rates proportional to BET surface areas? Geochim. Cosmochim. Acta 65, 1059-1070.

Golubev, S. V, Bénézeth, P., Dandurand, J.L., Schott, J., Castillo, A., 2009. Siderite dissolution kinetics in acidic aqueous solutions from 25 to $100{ }^{\circ} \mathrm{C}$ and 0 to $50 \mathrm{~atm} \mathrm{pCO}_{2}$. Chem. Geol. 265, 13-19. https://doi.org/10.1016/j.chemgeo.2008.12.031

Guo, H., Li, Y., Zhao, K., 2010. Arsenate removal from aqueous solution using synthetic siderite. J. Hazard. Mater. 176, 174-180.

Guo, H., Stüben, D., Berner, Z., 2007. Removal of arsenic from aqueous solution by natural siderite and hematite. Appl. Geochemistry 22, 1039-1051. 
https://doi.org/10.1016/J.APGEOCHEM.2007.01.004

Hangari, K.M., Ahmad, S.N., Perry, E.C., 1980. Carbon and oxygen isotope ratios in diagenetic siderite and magnetite from Upper Devonian ironstone, Wadi Shatti District, Libya. Econ. Geol. 75, 538-545.

Heywood, B.R., Mann, S., 1994. Template-directed nucleation and growth of inorganic materials. Adv. Mater. 6, 9-20.

Holland, H.D., 1984. The chemical evolution of the atmosphere and oceans. Princeton University Press.

Holland, H.D., 1972. The geologic history of sea water-an attempt to solve the problem. Geochim. Cosmochim. Acta 36, 637-651.

Huggett, J.M., Gale, A.S., McCarty, D., 2010. Petrology and palaeoenvironmental significance of authigenic iron-rich clays, carbonates and apatite in the Claiborne Group, Middle Eocene, NE Texas. Sediment. Geol. 228, 119-139.

Jiang, C.Z., Tosca, N.J., 2020. Growth kinetics of siderite at $298.15 \mathrm{~K}$ and 1 bar. Geochim. Cosmochim. Acta 274, 97-117.

Jiang, C.Z., Tosca, N.J., 2019. Fe(II)-carbonate precipitation kinetics and the chemistry of anoxic ferruginous seawater. Earth Planet. Sci. Lett. 506, 231-242. https://doi.org/10.1016/J.EPSL.2018.11.010

Jimenez-Lopez, C., Romanek, C.S., 2004. Precipitation kinetics and carbon isotope partitioning of inorganic siderite at $25 \mathrm{C}$ and $1 \mathrm{~atm}$. Geochim. Cosmochim. Acta 68, 557-571. 
Kolmogorov, A.N., 1937. On the statistical theory of the crystallization of metals. Bull. Acad. Sci. USSR, Math. Ser 1, 355-359.

Marqusee, J.A., Ross, J., 1984. Theory of Ostwald ripening: Competitive growth and its dependence on volume fraction. J. Chem. Phys. 80, 536-543.

Matsumoto, R., 1989. Isotopically heavy oxygen-containing siderite derived from the decomposition of methane hydrate. Geology 17, 707-710.

Matter, J.M., Broecker, W.S., Stute, M., Gislason, S.R., Oelkers, E.H., Stefánsson, A., WolffBoenisch, D., Gunnlaugsson, E., Axelsson, G., Björnsson, G., 2009. Permanent carbon dioxide storage into basalt: the CarbFix pilot project, Iceland. Energy Procedia 1, 36413646.

Mavromatis, V., Gautier, Q., Bosc, O., Schott, J., 2013. Kinetics of Mg partition and Mg stable isotope fractionation during its incorporation in calcite. Geochim. Cosmochim. Acta 114, $188-203$.

McMillan, S., Schwertmann, U., 1998. Morphological and genetic relations between siderite, calcite and goethite in a Low Moor Peat from southern Germany. Eur. J. Soil Sci. 49, 283293.

Montanari, G., Rodriguez-Blanco, J.D., Bovet, N., Stipp, S.L.S., Tobler, D.J., 2017. Impact of citrate ions on the nucleation and growth of anhydrous $\mathrm{CaCO}_{3}$. Cryst. Growth Des. 17, $5269-5275$.

Montes-Hernandez, G., Renard, F., 2016. Time-resolved in situ raman spectroscopy of the 
nucleation and growth of siderite, magnesite, and calcite and their precursors. Cryst. Growth Des. 16, 7218-7230.

Mortimer, R.J.G., Coleman, M.L., 1997. Microbial influence on the oxygen isotopic composition of diagenetic siderite. Geochim. Cosmochim. Acta 61, 1705-1711.

Noguera, C., Fritz, B., Clément, A., 2015. Precipitation mechanism of amorphous silica nanoparticles: A simulation approach. J. Colloid Interface Sci. 448, 553-563.

O'Grady, D., Barrett, M., Casey, E., Glennon, B., 2007. The effect of mixing on the metastable zone width and nucleation kinetics in the anti-solvent crystallization of benzoic acid. Chem. Eng. Res. Des. 85, 945-952.

Pandarinathan, V., Lepková, K., Van Bronswijk, W., 2014. Chukanovite $\left(\mathrm{Fe}_{2}(\mathrm{OH})_{2} \mathrm{CO}_{3}\right)$ identified as a corrosion product at sand-deposited carbon steel in $\mathrm{CO}_{2}$-saturated brine. Corros. Sci. 85, 26-32.

Parkhurst, D.L., Appelo, C.A.J., 2013. Description of input and examples for PHREEQC version 3--A computer program for speciation, batch-reaction, one-dimensional transport, and inverse geochemical calculations. Techniques and Methods.

Pekov, I. V, Perchiazzi, N., Merlino, S., Kalachev, V.N., Merlini, M., Zadov, A.E., 2007. Chukanovite, $\mathrm{Fe}_{2}\left(\mathrm{CO}_{3}\right)(\mathrm{OH})_{2}$, a new mineral from the weathered iron meteorite Dronino. Eur. J. Mineral. 19, 891-898.

Postma, D., 1983. Pyrite and siderite oxidation in swamp sediments. Eur. J. Soil Sci. 34, 163182. 
Postma, D., 1982. Pyrite and siderite formation in brackish and freshwater swamp sediments. Am. J. Sci. 282, 1151-1183.

Purgstaller, B., Mavromatis, V., Immenhauser, A., Dietzel, M., 2016. Transformation of Mgbearing amorphous calcium carbonate to Mg-calcite - In situ monitoring. Geochim. Cosmochim. Acta 174, 180-195. https://doi.org/10.1016/J.GCA.2015.10.030

Rodriguez-Blanco, J.D., Shaw, S., Benning, L.G., 2011. The kinetics and mechanisms of amorphous calcium carbonate (ACC) crystallization to calcite, via vaterite. Nanoscale 3, 265-271.

Sapota, T., Aldahan, A., Al-Aasm, I.S., 2006. Sedimentary facies and climate control on formation of vivianite and siderite microconcretions in sediments of Lake Baikal, Siberia. J. Paleolimnol. 36, 245-257.

Schott, J., Oelkers, E.H., Bénézeth, P., Goddéris, Y., François, L., 2012. Can accurate kinetic laws be created to describe chemical weathering? Comptes Rendus Geosci. 344, 568-585.

Schwertmann, U. t, Fischer, W.R., 1973. Natural "amorphous" ferric hydroxide. Geoderma 10, 237-247.

Shikazono, N., 1977. Composition of siderite and the environments of formation of vein-type deposits in Japan. Econ. Geol. 72, 632-641. https://doi.org/10.2113/gsecongeo.72.4.632

Snæbjörnsdóttir, S.Ó., Oelkers, E.H., Mesfin, K., Aradóttir, E.S., Dideriksen, K., Gunnarsson, I., Gunnlaugsson, E., Matter, J.M., Stute, M., Gislason, S.R., 2017. The chemistry and saturation states of subsurface fluids during the in situ mineralisation of $\mathrm{CO}_{2}$ and $\mathrm{H}_{2} \mathrm{~S}$ at the 
CarbFix site in SW-Iceland. Int. J. Greenh. Gas Control 58, 87-102. https://doi.org/10.1016/J.IJGGC.2017.01.007

Stumm, W., Lee, G.F., 1961. Oxygenation of ferrous iron. Ind. Eng. Chem. 53, 143-146.

Tobler, D.J., Blanco, J.D.R., Dideriksen, K., Sand, K.K., Bovet, N., Benning, L.G., Stipp, S.L.S., 2014. The Effect of Aspartic Acid and Glycine on Amorphous Calcium Carbonate (ACC) Structure, Stability and Crystallization. Procedia Earth Planet. Sci. 10, 143-148. https://doi.org/10.1016/J.PROEPS.2014.08.047

Tobler, D.J., Rodriguez-Blanco, J.D., Dideriksen, K., Bovet, N., Sand, K.K., Stipp, S.L.S., 2015. Citrate effects on amorphous calcium carbonate (ACC) structure, stability, and crystallization. Adv. Funct. Mater. 25, 3081-3090.

Tracy, S.L., Williams, D.A., Jennings, H.M., 1998. The growth of calcite spherulites from solution: II. Kinetics of formation. J. Cryst. Growth 193, 382-388.

Viollier, E., Inglett, P.., Hunter, K., Roychoudhury, A.., Van Cappellen, P., 2000. The ferrozine method revisited: $\mathrm{Fe}(\mathrm{II}) / \mathrm{Fe}(\mathrm{III})$ determination in natural waters. Appl. Geochemistry 15, 785-790. https://doi.org/10.1016/S0883-2927(99)00097-9

Voigt, M., Clark, D.E., Gíslason, S.R., Oelkers, E.H., 2018. Evaluation and refinement of thermodynamic databases for mineral carbonation. Energy Procedia 146, 81-91. https://doi.org/10.1016/J.EGYPRO.2018.07.012

Wang, Y.-W., Kim, Y.-Y., Stephens, C.J., Meldrum, F.C., Christenson, H.K., 2012. In situ study of the precipitation and crystallization of amorphous calcium carbonate (ACC). Cryst. 
Growth Des. 12, 1212-1217.

William, J., Mehl, R., 1939. Reaction kinetics in processes of nucleation and growth. Trans. Met. Soc. AIME 135, 416-442. 